\title{
A POBREZA INFANTIL E O RENDIMENTO SOCIAL DE INSERÇÃO EM PORTUGAL O mesmo problema, tendências distintas
}

\author{
Fernando Diogo \\ Universidade dos Açores, CICS.NOVA.UAc/CICS.UAc
}

Resumo Este artigo centra-se na constatação de que a proporção de crianças (0-17 anos) entre os beneficiários do Rendimento Social de Inserção (RSI) está a descer consistentemente desde há alguns anos, em contraste com uma taxa de pobreza infantil persistentemente alta. Esta contradição é demonstrada através da exploração dos dados sobre o RSI cruzados com as estatísticas do INE referentes à pobreza infantil (ICOR-EU-SILC), medida com base na pobreza monetária. É desenvolvida uma hipótese para explicar esta contradição, assente nas transformações legais do RSI e na dificuldade do estado em desenvolver medidas de apoio social com impacto na pobreza infantil.

Palavras-chave: pobreza infantil, Rendimento Social de Inserção, estatísticas.

Abstract This paper focuses on the finding that the proportion of children (0-17 years) among the recipients of Social Integration Income (RSI) has been consistently declining for several years in contrast to a persistently high child poverty rate. This contradiction is demonstrated thru the use of RSI data cross-referenced with INE statistics on child poverty (ICOR-EU-SILC), measured by monetary poverty. A hypothesis is developed to explain this contradiction based on the legal transformations of the RSI and the difficulty of the state to develop measures of social support with impact on child poverty.

Keywords: child poverty, social integration income, statistics.

Résumé Cet article se centre sur le constat selon lequel le pourcentage d'enfants (0-17 ans) parmi les bénéficiaires du Revenu Social d'Insertion (RSI) connaît une baisse constante depuis quelques années, tandis que celui de pauvreté infantile reste élevé. Cette contradiction est démontrée en croisant les données sur le RSI avec les statistiques de l'Institut National de la Statistique (INE) sur la pauvreté infantile (ICOR-EU-SILC), mesurée d'après la pauvreté monétaire. Une hypothèse est avancée pour expliquer cette contradiction, fondée sur les changements de la législation applicable au RSI et sur la difficulté de l'État à adopter des mesures d'aide sociale ayant un impact sur la pauvreté infantile.

Mots-clés: pauvreté infantile, revenu social d'insertion, statistiques.

Resumen Este artículo se centra en la constatación de que la proporción de niños (0-17 años) entre los beneficiarios del Rendimiento Social de Inserción (RSI) está disminuyendo consistentemente desde hace algunos años en contraste con una persistente y elevada tasa de pobreza infantil. Esta contradicción está demostrada a través de la utilización de los datos sobre el RSI comparados con las estadísticas del INE referentes a la pobreza infantil (ICOR-EU-SILC), medida con base en la pobreza monetaria. Se desarrolla una hipótesis para explicar esta contradicción basada en las transformaciones legales del RSI y en la dificultad del estado para desarrollar medidas de apoyo social con impacto en la pobreza infantil.

Palabras-clave: pobreza infantil, rendimiento social de inserción, estadísticas.

\section{Introdução}

Este artigo centra-se na ideia de que a proporção de crianças (0-17 anos) entre os beneficiários do Rendimento Social de Inserção (RSI) está a descer desde há alguns 
anos. ${ }^{1}$ Procura-se demonstrar que esta descida é feita em contraste com uma taxa de pobreza infantil persistentemente alta. Esta demonstração é feita através da exploração dos dados estatísticos do INE referentes à taxa de risco de pobreza infantil ao longo do tempo, medida com base na pobreza monetária, e dos dados sobre o RSI. São problematizadas a evolução, configuração e comparação desta taxa de risco de pobreza com taxas de outras categorias sociais apresentadas pelo INE. Ou seja, para além dos dados sobre a relação entre pobreza infantil e RSI, são explorados outros dados do ICOR-EU-SILC ${ }^{2}$ que nos permitem compreender a centralidade desta forma de pobreza na sociedade portuguesa.

Por fim, avançamos com uma hipótese explicativa para a contradição entre uma taxa de pobreza infantil persistentemente elevada por contraponto com a redução paulatina ao longo dos anos da proporção desta faixa etária entre os beneficiários do RSI.

Contudo, o artigo começará por discutir os fatores que permitem considerar a pobreza infantil como um objeto autónomo em relação à pobreza em geral para, de seguida, refletir sobre as limitações associadas à taxa de pobreza infantil utilizada pelo INE. Este exercício permitirá ler os dados estando conscientes das suas limitações e, dessa forma, concluir com mais segurança.

\section{A pobreza infantil como conceito, limites e potencialidades}

O conceito de pobreza infantil apresenta especial complexidade no contexto das ciências sociais. Esta complexidade deriva de diversos fatores que, por uma questão de organização, dividimos em externos e internos ao conceito.

No que diz respeito aos fatores externos, a questão que se releva é que o conceito resulta da conjugação de dois outros conceitos desenvolvidos a montante: pobreza e infância. Cada um deles é, por si só, polissémico e alvo de diversas aceções (Diogo, 2010). A sua conjugação vem, obviamente, amplificar as dificuldades conceptuais que cada um deles encerra, mesmo considerando que o conceito de pobreza infantil não se refere a uma simples justaposição de pobreza e infância, como abaixo se discute.

Em relação aos fatores internos, estão em causa duas ideias principais. A primeira está associada à própria definição de infância, pois consideram-se crianças pobres indivíduos até aos 17 anos. Este limite etário é, em boa parte, arbitrário e contestável (Almeida, 2009; Diogo, 2010), mas isso não o impede de ser amplamente utilizado inclusive neste artigo. ${ }^{3}$ Não obstante a sua utilidade, traduzida nessa

1 O autor agradece a Rui Santo e Márcio Rocha o apoio prestado em relação ao RSI, bem como ao Conselho Diretivo do Instituto de Segurança Social dos Açores.

Inquérito às Condições de Vida e Rendimento (Statistics on Income and Living Conditions).

O limiar de 0 a 17 anos tem sido usado como sendo o de pobreza infantil em trabalhos em Portugal, como Bastos e Nunes (2009). A nível internacional a UNICEF (2016: 44), bem como a OECD (2009), usam o mesmo grupo de idades para definir pobreza infantil. O fundamento desta utilização está na definição de criança das Nações Unidas (OECD, 2009: 29), centrada, precisamente, nos 0-17 anos. 
ampla utilização, o intervalo de idades considerado e as fases da vida que compreende (do ponto de vista biológico e social) obrigam a que se tenha de utilizá-lo com especial cuidado. Basta pensar em tudo o que separa uma criança de um ou dois anos de um jovem de 15 ou 16.

Sobre este último problema, diga-se que a infância se interceta com outras fases da vida: a juventude (sem esquecer a adolescência) e a idade adulta (Almeida, 2009), dado que as suas fronteiras são socialmente definidas e, por isso, difusas e fluidas.

A segunda ideia está associada à forma de medir a pobreza infantil: as crianças não são unidades de registo estatístico, dado que não são titulares de rendimentos (Bruto da Costa, 2015: 10). ${ }^{4}$ Estão, aliás, legalmente proibidas de trabalhar. As crianças são pobres no seio de unidades familiares pobres (Diogo, 2010: 21; Bastos, 2015: 110) ou quando não se enquadram em famílias que lhes forneçam recursos de diversos tipos. ${ }^{5}$ São estes recursos que permitem configurar as capacidades de que as crianças precisam para sobreviverem e se construírem como adultos.

Acresce que existem outras questões que complexificam a ideia de pobreza infantil, designadamente os problemas estatísticos e o impacto da crise na pobreza.

Quanto ao impacto da crise, é relevante a ideia de que sabemos pouco sobre esse assunto, os dados são escassos e, mais do que isso, recolhidos e publicados com atraso, algo que limita o alcance das medidas políticas neles baseadas (Capucha, 2015: 54 e ss.).

As estatísticas não são suficientes para qualificarmos a evolução do fenómeno. Podemos perceber que a crise está a ter um efeito na pobreza e na pobreza infantil mas não temos informações suficientes para compreender as principais questões estruturantes e as principais transformações. Os indicadores que o INE fornece são quantitativos e limitados a questões monetárias (direta ou indiretamente).

Uma outra questão relevante respeita aos problemas estatísticos, estes estão relacionados com o facto de o limiar de pobreza monetária utilizado para a medir ter uma boa dose de arbitrariedade (D'Agostino e Duvert, 2008: 15). Na OCDE e nos EUA, por exemplo, é usado um limiar de $50 \%$ da mediana e não $60 \%$ como na UE (vide OECD, 2011: 318).

Acresce que a mediana é uma medida sensível aos decréscimos de rendimento, por contraponto a outras medidas usadas habitualmente na análise da pobreza. Por este motivo o INE (e o Eurostat) tem vindo a fazer o exercício de calcular a taxa de pobreza ancorada a 2009 (dado que neste ano se começaram a fazer sentir em força os efeitos da crise financeira e económica na Europa). Este tratamento estatístico permite ter uma noção mais realista da evolução da pobreza em Portugal (para mais pormenores sobre esta questão cf., por exemplo, Diogo, 2016).

4 A não titularidade de recursos pelas crianças é claramente um reflexo da forma como a sociedade está organizada, pois noutros contextos sociais e no passado as crianças são e foram titulares de rendimentos.

5 Neste sentido, a tipologia de capitais desenvolvida por Bourdieu é um bom instrumento para se compreender a diversidade dos recursos existentes na sociedade. 
É preciso ainda ter em atenção, no que aos problemas estatísticos respeita, que as estatísticas oficiais são apenas indicadores do problema da pobreza e não nos dão informação sobre um conjunto diversificado mas pertinente de temáticas relacionadas com esta.

Neste sentido, e a título de exemplo, identificamos diversas áreas que vale a pena aprofundar para melhor compreender o problema da pobreza em Portugal e fundamentar políticas mais adequadas: (i) as tipologias de pobreza, onde se encontram os modos de vida da pobreza ${ }^{6}$ e os distintos perfis de pobre; (ii) as formas como os indivíduos em situação de pobreza lidam com os seus impactos identitários (identidade social) e com os problemas associados à condição de pobreza; (iii) os dados sobre os fluxos de entrada, permanência e saída da pobreza (i.e. sobre a estruturalidade da pobreza) $;^{7}$ (iv) a distribuição no território nacional (os dados por NUTS II do IDEF ${ }^{8}$ não são suficientes para desempenhar esse papel); (v) a relação dos pobres com a escola e com a escolaridade; (vi) a relação dos pobres com o mundo do trabalho e com a formação profissional; (vii) a saúde dos pobres e a sua relação com o sistema de saúde; e (viii) a relação dos pobres com os sistemas de apoio social, em particular com a Segurança Social, as instituições (IPSS) ${ }^{9}$ e, num registo mais microssocial, com as assistentes sociais em particular. ${ }^{10}$

Das questões acima elencadas apenas a referente aos fluxos (ponto iii) pode ser obtida através da análise aprofundada dos dados estatísticos disponibilizados pelo INE. De resto, poucos são os estudos e os dados que em Portugal têm sido desenvolvidos que transcendam o trabalho com as estatísticas oficiais. É claro que existem estudos sobre as questões acima elencadas em Portugal. No entanto, o seu número é relativamente modesto, por comparação com outras questões sociais pertinentes, como a educação e suas políticas ou as questões referentes ao emprego, só para elencar dois exemplos pertinentes. ${ }^{11} \mathrm{O}$ número dos que não se baseiam em fontes estatísticas é pequeno e alguns não têm como referente central a questão da pobreza, e raros são os que têm algum tipo de representatividade estatística para o conjunto do território português. Daqui resulta que, em nosso entender, a acumulação de conhecimentos é um processo que ainda está em boa parte por fazer no que respeita às diversas questões que a pobreza suscita.

6 Sobre esta questão é de destacar o trabalho pioneiro de Luís Capucha (2005).

7 A estruturalidade da pobreza está associada à sua reprodução ao longo de gerações e à sua persistência na vida dos indivíduos, quando vista a partir dos atores sociais. Ao mesmo tempo, está associada às estruturas sociais que condicionam a vida dos indivíduos e que não dependem deles, como a configuração e transformações no mercado de trabalho e as desigualdades de distribuição de rendimento, para citar dois exemplos relevantes (mas que não esgotam os traços estruturantes).

8 Inquérito às Despesas das Famílias. Sobre este aspeto o trabalho pioneiro de Elvira Pereira (2010) não pode ser ignorado.

9 Instituições particulares de solidariedade social.

10 A propósito do trabalho das assistentes sociais enquadrado em diversos tipos de instituições e da sua relação com os beneficiários, releve-se o trabalho feito nos últimos anos pelos investigadores em Serviço Social, como por exemplo Francisco Branco (2015).

11 Para uma nota recente relativa aos estudos sobre a pobreza em Portugal veja-se Diogo, Castro e Perista (2015). 
De notar que estas temáticas se cruzam, quase todas, com as questões específicas da pobreza infantil. Destacam-se, no entanto, os pontos iii, v e vii como particularmente pertinentes no contexto desta forma específica de pobreza.

Não obstante as dificuldades conceptuais que aconselham prudência no uso do conceito de pobreza infantil e que acima elencámos, defendemos a sua utilização, porque as especificidades sociais e biológicas que fazem da infância uma idade da vida singular também atuam para fazer da pobreza infantil um problema e um objeto específico. As crianças têm características e necessidades próprias, distintas das dos adultos, cuja análise e compreensão é mal acomodada pelo conceito geral de pobreza (Diogo, 2010, 2016). Quer isto dizer que faz sentido falar de pobreza infantil pelo facto de fazer sentido falar de crianças e de infância.

Acrescente-se que infância e juventude apresentam como condição comum o facto de ambas implicarem a dependência social e financeira das famílias de enquadramento, algo que mitiga o problema da amplitude etária do conceito, fundamentando a opção por uma faixa etária tão alargada.

Finalmente, a utilização desta faixa etária acaba por ser uma imposição quer da literatura, que a usa (dada a necessidade de comparação), quer do facto de os dados estarem assim organizados nas estatísticas oficiais sobre a pobreza, a nível nacional e internacional. ${ }^{12}$

\section{A evolução da pobreza e da pobreza infantil em Portugal}

Estabelecidas que estão as limitações e potencialidades da análise da pobreza infantil, em termos empíricos, o primeiro dado importante para compreendermos a relação entre Rendimento Social de Inserção (RSI) e pobreza infantil respeita à análise da evolução comparada da taxa de pobreza com a taxa de pobreza infantil em Portugal (indicador monetário). ${ }^{13}$ Estes dados permitem-nos estabelecer a centralidade do problema da pobreza no país e compreender como é que a pobreza infantil se posiciona em relação à pobreza em geral.

A taxa de pobreza (taxa de risco de pobreza no léxico do INE) encontra-se, desde 2003 , no intervalo entre os $15 \%$ e os $20 \%$ da população residente, mas mais próxima do limite superior. Aliás, em 2003 chegou aos 20,4\% e em anos recentes, a partir de 2010, tem vindo a aproximar-se deste limite, tendo-se fixado em 19,5\% em 2013 e 2014, descendo para 19,0\% em 2015. Isto mesmo tendo em consideração a redução do valor da mediana de rendimento por adulto equivalente, por via da redução dos rendimentos dos portugueses (Diogo, 2016; Rodrigues, Figueiras e Junqueiro, 2016). Para o último ano para o qual existem dados, 2015, quase um em

12 O INE vai ao ponto de considerar crianças os "indivíduos entre 18 e 24 anos economicamente dependentes" para o cálculo da taxa de pobreza por agregado familiar. Este exercício mostra bem que o fator tido em consideração na definição de criança em causa é a menoridade social expressa na dependência económica.

13 Embora o INE e o Eurostat se refiram a taxa de risco de pobreza, optou-se por simplificar a designação retirando o termo risco, dado que não se vislumbra pertinência na sua utilização. 


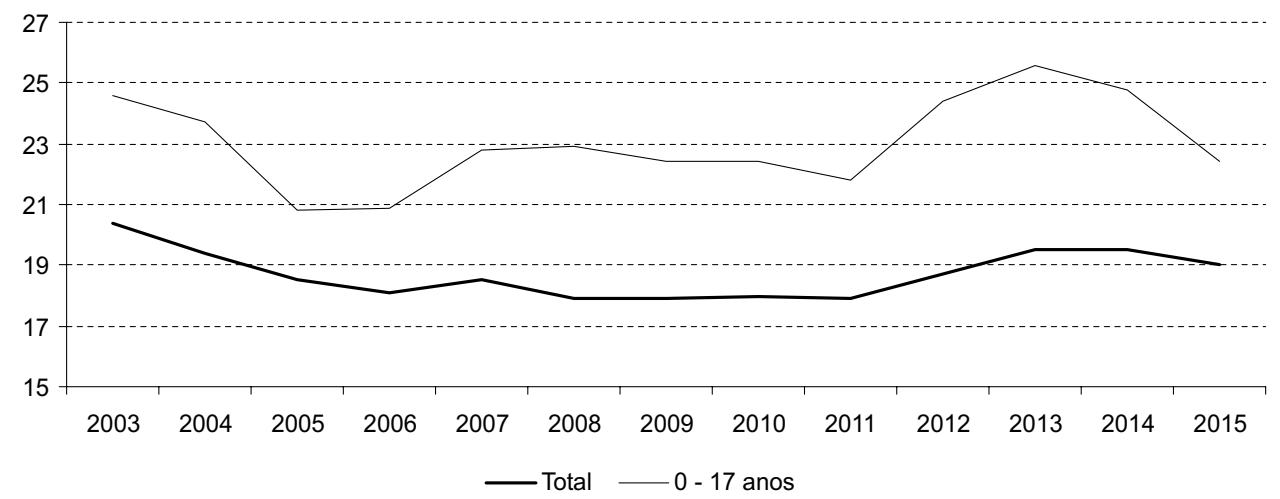

Figura 1 Taxa de risco de pobreza em Portugal, total e 0-17 anos (2003-2015)

Fonte: INE, ICOR-EU-SILC.

cada cinco portugueses está em situação de pobreza, algo que mostra bem a relevância do problema na sociedade portuguesa.

A taxa de pobreza infantil (0-17 anos) apresenta um valor que é sempre mais elevado do que a taxa geral. De notar que entre 2014 e 2015 esta taxa de pobreza registou uma redução bastante significativa, cifrada em 2,4 pontos percentuais (pp). A diferença média para o período em análise (2003-2015) é de 4,3 pp. Desde 2012, essa diferença aumentou para valores acima dos $5 \mathrm{pp}$, tendo-se registado uma queda abrupta em 2015, ano em que se cifrou em 3,4 pp.

Pode colocar-se a hipótese de que são as alterações nas transferências sociais que fazem a diferença, mas não parece ser o caso. Como podemos ver no quadro 1 , as transferências sociais (incluindo pensões) têm um impacto muito limitado entre as crianças e não se verifica nenhum padrão de aumento do seu peso. Pelo contrário, entre 2014 e 2015 pode verificar-se um ligeiro decréscimo.

A pobreza infantil pode ainda ser percecionada a partir de outros dados disponibilizados pelo INE (no ICOR-EU-SILC), designadamente através da análise da pobreza por grupos etários e da composição do agregado familiar (figuras 2 e 3).

A evolução dos comportamentos das taxas de pobreza por grupos etários é clara. Todos estão abaixo da taxa geral (total) menos o que corresponde às crianças (0-17 anos). Mais, em termos de evolução salienta-se o grupo dos de 65 e mais anos, que vê a sua taxa passar de mais alta em 2003 para mais baixa em 2015, apesar do agravamento verificado nos anos mais recentes. Em contraste, a taxa de pobreza infantil mantém-se acima da taxa geral e, nos últimos anos, viu mesmo a sua distância em relação a esta agravar-se (apesar da inversão de tendência esboçada a partir de 2013, ano em que atingiu o valor máximo).

Um outro indicador disponível para se compreender melhor a pobreza infantil respeita à composição do agregado familiar. Este indicador está construído nos dados do ICOR-EU-SILC de forma a relevar a presença nas famílias de três variáveis: (i) a dimensão do agregado; (ii) a presença de idosos; e (iii) a presença de 
Quadro 1 Diferenças nas taxas de pobreza em pontos percentuais, base: antes de qualquer transferência social

\begin{tabular}{clcc}
\hline & & $\begin{array}{c}\text { Após transferências } \\
\text { sociais }\end{array}$ & $\begin{array}{c}\text { Após transferências } \\
\text { de pensões }\end{array}$ \\
\hline \multirow{2}{*}{2012} & Total & $-6,8$ & $-21,4$ \\
& $0-17$ anos & $-7,3$ & $-3,7$ \\
& $18-64$ anos & $-7,9$ & $-11,5$ \\
& $65+$ anos & $-2,8$ & $-69,6$ \\
\hline & Total & $-7,2$ & $-21,1$ \\
& $0-17$ anos & $-8,9$ & $-10,5$ \\
& $18-64$ anos & $-8,3$ & $-70,4$ \\
\hline \multirow{3}{*}{2014} & $65+$ anos & $-3,4$ & $-21,4$ \\
& Total & $-6,9$ & $-3,3$ \\
& $0-17$ anos & $-6,5$ & $-10,6$ \\
& $18-64$ anos & $-8,3$ & $-70,1$ \\
\hline & $65+$ anos & $-3,2$ & $-21,2$ \\
& Total & $-6,1$ & $-3,0$ \\
& $0-17$ anos & $-6,2$ & $-10,4$ \\
& $18-64$ anos & $-7,1$ & $-68,6$ \\
\hline
\end{tabular}

Fonte: INE, ICOR-EU-SILC

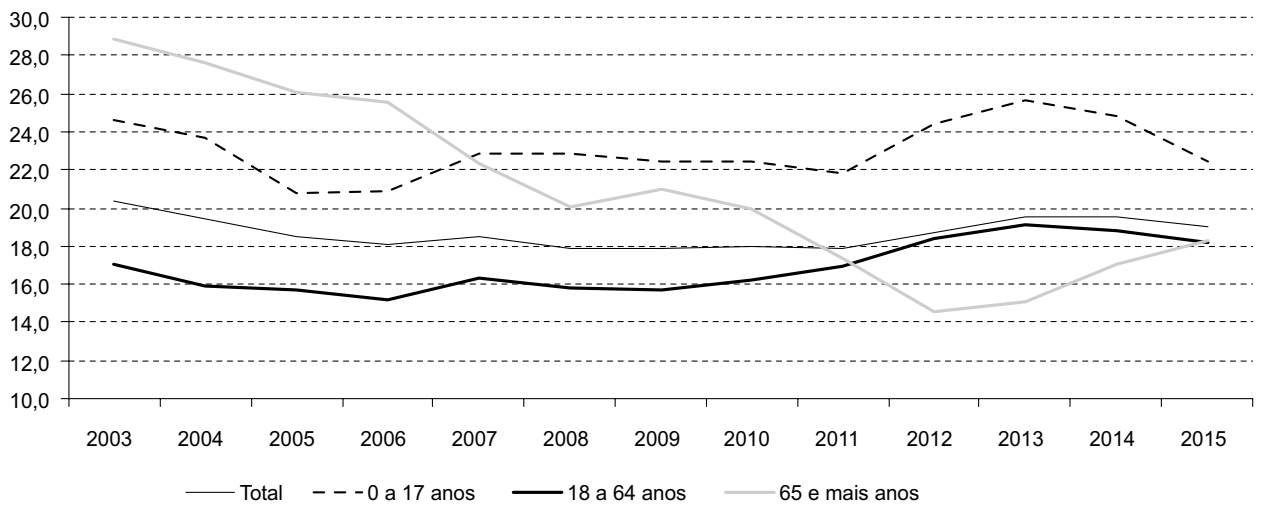

Figura 2 Taxa de risco de pobreza, por grupos etários

Nota: Em relação às diferenças entre grupos etários, Amélia Bastos (2015: 106) mostra que, entre 2004 e 2012 com base nos dados do ICOR-EU-SILC, o grupo etário com maior e mais consistente risco de pobreza é, precisamente, o constituído pelas crianças (0-17 anos).

Fonte: INE, ICOR-EU-SILC.

crianças. A sua relevância para este artigo diz respeito ao destaque dado à presença de crianças nos agregados (figura 3).

Os dados permitem perceber, em primeiro lugar, que em 2015 os agregados familiares com crianças têm uma taxa de pobreza superior à média, estando acima das diversas modalidades de agregados sem crianças. Para o ano em análise, a distância entre estes dois tipos de agregado foi de 4,2 pp (melhor que os 5,6 pp de 


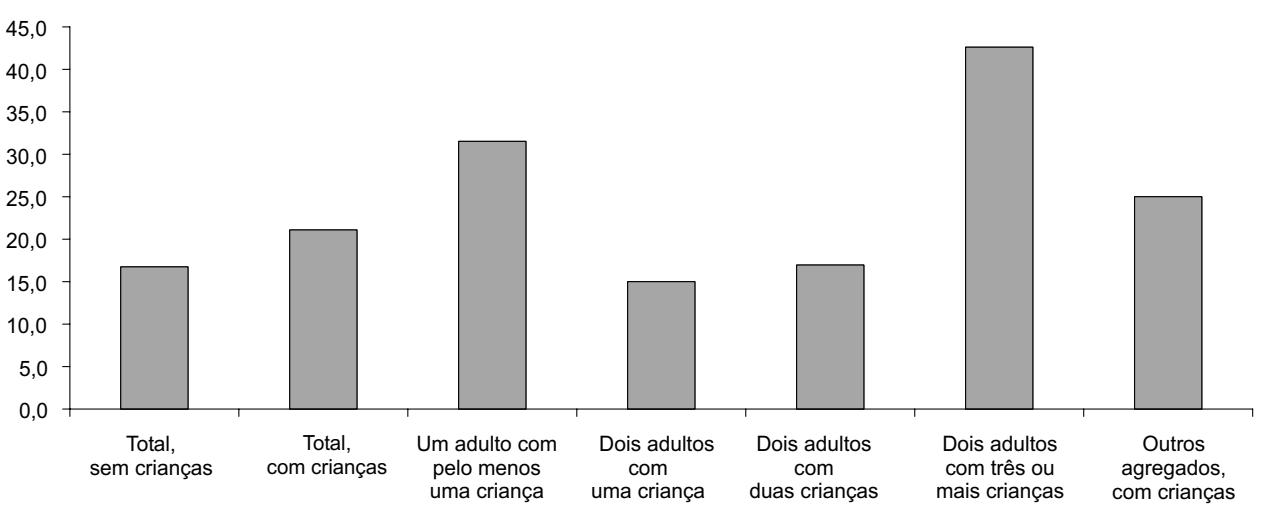

Figura 3 Taxa de risco de pobreza, por composição do agregado familiar, 2015

Fonte: INE, ICOR-EU-SILC.

2014). Trata-se de um resultado teoricamente esperado: se a taxa de pobreza infantil é maior que a taxa geral e se as crianças são pobres no seio de agregados familiares pobres, então a taxa de pobreza de agregados familiares com crianças deverá ser superior à de agregados sem crianças, como de facto se verifica.

Uma análise mais esmiuçada permite perceber que as maiores taxas de pobreza por tipo de agregado respeitam a dois adultos com três e mais crianças (agregados numerosos) e a um adulto com pelo menos uma criança. Este último caso corresponderá, cremos, a famílias monoparentais femininas, já identificadas pela literatura como sendo particularmente vulneráveis à pobreza (Capucha, 2005: 192 e ss.; e Pereirinha et al., 2008: 15).

Comparemos, pois, a evolução da taxa dos agregados de dois adultos com três e mais crianças e um adulto com pelo menos uma criança com a taxa da pobreza geral (figura 4).

Podemos observar que as famílias com crianças dependentes nem sempre tiveram uma taxa de pobreza superior à taxa geral. É a partir de 2007 que a distância entre as duas se vinca, tendo-se agravado a partir de 2010 (embora em 2014 tenha descido pela primeira vez desde o início da crise). Analisemos, de seguida, as outras duas categorias consideradas.

Se a taxa de pobreza das famílias com crianças tem vindo a agravar-se (mesmo com a mudança de tendência a partir de 2014) o mesmo não pode ser dito em relação às famílias monoparentais (um adulto com uma ou mais crianças) e às numerosas (dois adultos com três ou mais crianças). Estas últimas apresentam resultados, apesar das flutuações anuais, consistentemente acima da taxa de pobreza para as famílias com crianças. Esta consistência temporal pode ser lida como uma manifestação da estruturalidade da pobreza (Alves, 2015; Bastos, 2015; Capucha, 2005; Batista e Perista, 2010) para determinado tipo de famílias, de categorias sociais e de indivíduos na sociedade portuguesa. Neste caso, está em causa a estruturalidade da pobreza para determinado tipo de famílias com crianças. 


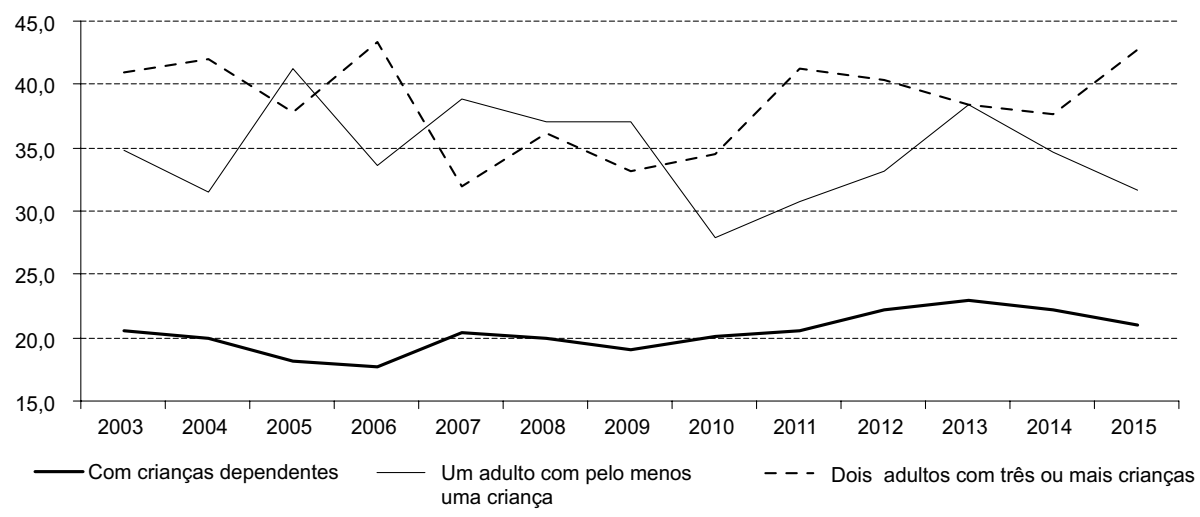

Figura 4 Taxa de risco de pobreza, por composição do agregado familiar, (2003-2015), categorias selecionadas

Fonte: INE, ICOR-EU-SILC.

Ora, do ponto de vista teórico este tipo de famílias encaixa-se no perfil potencial dos beneficiários do RSI. A forma como esta medida de apoio social é calculada (e que determina o acesso à prestação pecuniária) permite a estes dois tipos de família serem beneficiários se se verificarem as seguintes condições:

i. No caso das famílias monoparentais, o que está em causa é algo que corresponde, simultaneamente, à condição básica de acesso ao RSI e à forma como é calculado o direito de acesso à medida (cf. Diogo, 2016): a ausência de recursos. Neste tipo de família, mesmo um ordenado muito baixo coloca-a, muito provavelmente, acima do limiar a partir do qual se constitui o direito a receber a prestação. A elevada taxa de pobreza deste tipo de agregado é indicadora da inexistência desse ordenado mínimo em muitas famílias e também da sua potencial elegibilidade para o RSI.

ii. No caso das famílias numerosas existe outra possibilidade, mesmo com rendimentos familiares e atividade profissional (de pelo menos um dos membros do agregado familiar): o direito a receber-se a prestação deriva da escassez relativa dos rendimentos em relação ao total dos membros da família, quer dizer está associado à capitação.

Os dados do RSI que apresentamos de seguida, fornecidos pela Segurança Social, não permitem aprofundar uma análise por tipo de agregado familiar. Contudo, as elevadas taxas de pobreza que os agregados familiares mais numerosos e monoparentais apresentam indicam claramente que estes dois tipos de agregado são os que mais se encontram em condições de elegibilidade para esta medida de apoio social. Logo, é de esperar um elevado número de crianças entre os beneficiários. 


\section{O RSI: o que é e como é que as crianças se encaixam nesta medida}

Está, pois, estabelecida a centralidade da pobreza na sociedade portuguesa e a relevância da pobreza infantil no contexto da pobreza em Portugal. Está, também, claro qual tem sido a evolução ao longo do tempo destas duas taxas de pobreza bem como as suas limitações teóricas. Acresce que foi ainda possível conhecer alguns detalhes sobre a pobreza infantil através da análise dos indicadores relativos à composição dos agregados familiares em situação de pobreza. Em especial, foi possível perceber que existem dois tipos de agregados familiares com crianças (e jovens) que são especialmente vulneráveis à pobreza. Resta perceber como é que o comportamento da taxa de pobreza infantil se articula com o RSI.

A primeira questão que se coloca é: como é que as crianças recebem o RSI? E a resposta é: de forma indireta. Nesta medida de apoio social, beneficiário é distinto de titular, dado que beneficiários são todos os que, num dado agregado familiar, contam para o cálculo da prestação e estão disponíveis para se enquadrarem em programas de inserção, algo que é diferente de titular, que é a pessoa que requer e recebe a prestação em nome do seu agregado familiar. Portanto, as crianças (e jovens) são beneficiárias do RSI e não são titulares da prestação. O que está aqui em causa é a conceção das crianças e jovens como dependentes da sua família fazendo com que até aos 18 anos só possam ser titulares em condições muito excecionais. Crianças e jovens até esta idade não são titulares de rendimentos, como acima ficou vincado.

Por outro lado, ser beneficiário do RSI implica que se esteja bastante abaixo do limiar de pobreza. Nem todos os pobres têm direito a receber esta prestação social, longe disso. Com dados de 2012, calculámos que só indivíduos com rendimentos inferiores a $20 \%$ ou a $38 \%$ do limiar da pobreza é que têm a possibilidade de beneficiar desta medida de apoio social (Diogo, 2016). No RSI não existe um limiar único e fixo, dado que a prestação depende da composição do agregado familiar, no primeiro caso foi calculado o limiar do RSI para uma família de dois adultos e duas crianças e no segundo para um isolado, dois casos típicos que nos ajudam a perceber os limites monetários desta medida.

Relativamente à proporção de indivíduos até aos 17 anos entre os beneficiários, o que os dados nos permitem perceber é que esta não tem parado de se reduzir, tendo-se fixado em menos de um terço do total em 2015. Algo que contradiz a possibilidade de existir uma maior incidência de crianças entre os beneficiários, dada a maior incidência da pobreza nos agregados familiares com crianças.

A comparação entre a taxa de pobreza das famílias com crianças e a taxa de pobreza infantil, por um lado, com a proporção de crianças entre os beneficiários do RSI (em percentagem), por outro, permite perceber claramente que o número de crianças entre os beneficiários está em redução em contraciclo com o aumento da pobreza infantil desde pelo menos 2006. Mais, verifica-se que esta tendência sofreu um agravamento substancial a partir de 2010. Esta última data não é certamente casual, dadas as alterações no RSI introduzidas para se reduzir os gastos com as prestações sociais, em consequência da crise (vide, a propósito das crianças, Wall, et al., 2015: 22; e Sarmento, Fernandes e Trevisan, 2015: 87; 


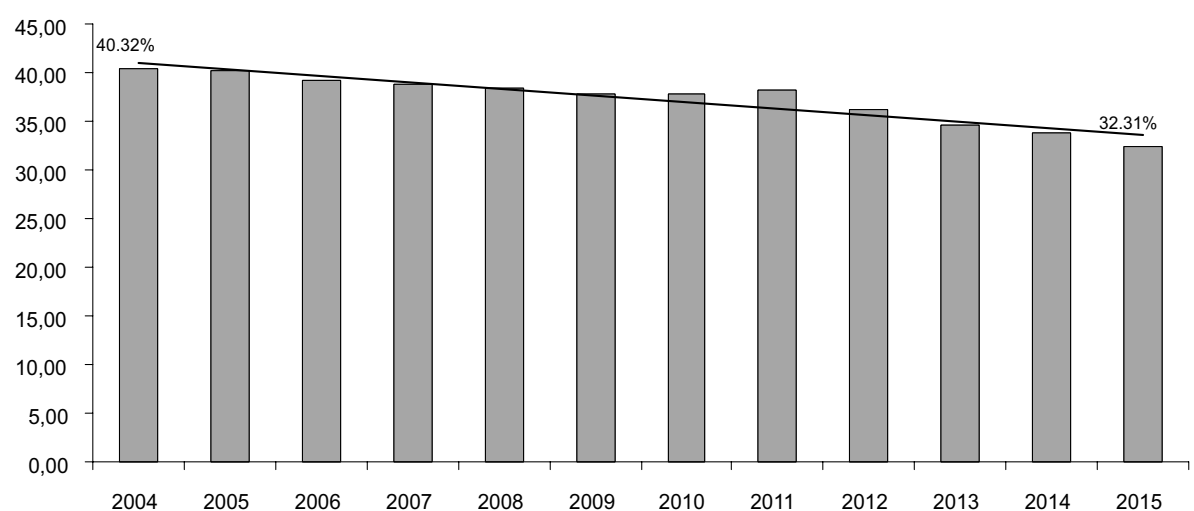

Figura 5 Evolução da proporção de beneficiários 0-17 anos no total, 2004-2015

Fonte: Segurança Social.

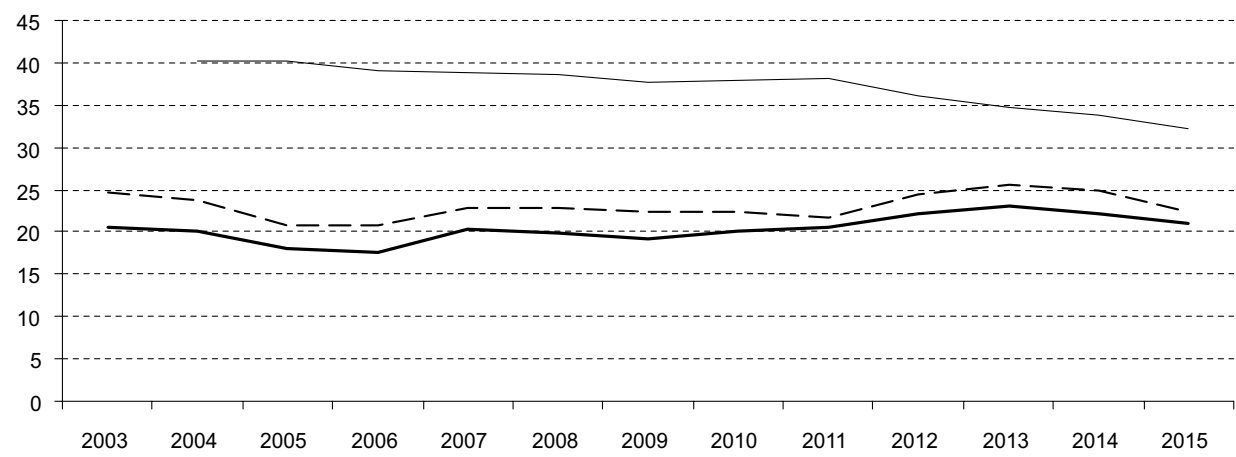

- Com crianças dependentes - Benef. \% 0-17 no total $\quad-\quad-$ T. Pob 0 - 17 anos

Figura 6 Comparação entre taxa de pobreza infantil, taxa de pobreza para famílias com crianças dependentes e proporção de crianças beneficiárias (0-17 anos) no total dos beneficiários (2003-2015)

Nota: O RSI surge em 2004 substituindo o rendimento mínimo garantido, pelo que só há dados a partir desse ano.

Fontes: Segurança Social e INE, ICOR-UE-SILC.

sobre a redução das prestações sociais por efeito da crise vide Rodrigues, Figueiras e Junqueiro, 2016).

Em relação às transformações legais do RSI com impacto no volume de beneficiários é preciso ter em atenção, em primeiro lugar, que entre 2003 e 2004, com a publicação da Lei N. ํ. 13/2003, deu-se a transição do RMG (rendimento mínimo garantido) para o RSI. Existiram, portanto, nesse período, duas medidas com 
Quadro 2 Principais transformações do RSI, 2003-2016

2003-2004: Passagem do RMG para o RSI

- Duplicação de dados. $\left(^{*}\right)$

- Maior complexidade para se requerer a prestação.

Decreto-Lei N. ${ }^{\circ}$ 70/2010, de 16 de junho

- Redução da prestação por via da redução dos apoios complementares.

Decreto-Lei N. ${ }^{\circ} 133 / 2012$, de 27 de junho

- Redução dos montantes máximos a atribuir por família.

- Redução do peso dos indivíduos no cálculo da prestação (adoção da escala de equivalências da OCDE).

- Obrigatoriedade prévia do acordo de inserção e fim da renovação automática vêm complexificar a prestação e

adiar o seu recebimento, levando a menos beneficiários

- Inclusão de todos os habitantes da mesma casa no cálculo da prestação leva à redução do número de beneficiários. $\left({ }^{* *}\right)$

Orçamento de Estado 2013

- Redução do montante da prestação via diminuição em $6 \%$ da percentagem do indexante de apoios sociais (419,22 euros), passando para $42,495 \%$ deste valor.

Alterações posteriores a 2013

- Em 2014 e 2015 não se registaram alterações com impacto na prestação ou na sua forma de cálculo.

- Em 2016 modificou-se a escala de equivalência referente ao agregado familiar, algo que se traduziu num

aumento do peso de cada indivíduo maior, de $50 \%$ para $70 \%$ (do valor de referência do RSI) e de cada indivíduo menor, de $30 \%$ para $50 \%$.

- Nesse mesmo ano o valor de referência do RSI passa para $43,173 \%$ do indexante de apoios sociais e 180,99 euros, e em 2017 passa, respetivamente, para $43,634 \%$ e 183,84 euros.

Notas: $\left(^{*}\right)$ Alguns indivíduos foram contabilizados simultaneamente no RMG e no RSI, dado que a transição implicou que no mesmo ano tenham estado numa e na outra medida aparecendo nas estatísticas das duas. ${ }^{* *}$ Indivíduos e núcleos familiares (por exemplo filhos maiores casados) com rendimentos acima do limiar do RSI e residentes na mesma habitação que os candidatos a beneficiários passaram a ser contabilizados para o cálculo do rendimento familiar elevando-o acima do limiar a partir do qual se verifica o direito ao recebimento da prestação.

Fonte: Segurança Social, Divisão de Ação Social de Ponta Delgada e levantamento e análise própria.

beneficiários e bases de dados distintas. Apesar disso, em termos substantivos as diferenças entre RMG e RSI são mínimas (Diogo, 2007), pelo que, salvaguardando-se algumas cautelas na análise dos dados, existe continuidade.

Em segundo lugar, as alterações sucessivas na legislação vêm reduzir o número de beneficiários e o volume das prestações, como se vê no quadro 2. Só a partir de 2016 é que se voltam a registar alterações com efeitos positivos nos montantes recebidos e no número de beneficiários.

Pode-se concluir, através das análises apresentadas, que se se verifica uma redução no número de beneficiários esta é concomitante com a progressiva perca de importância do grupo das crianças (e jovens) no total dos beneficiários.

A questão que se coloca é: como interpretar esta flagrante contradição? De facto estamos perante duas contradições: (i) a primeira respeita à redução do número de beneficiários do RSI num contexto de aumento da pobreza, (ii) a segunda respeita à redução da proporção das crianças (0-17 anos) entre os beneficiários do RSI num contexto em que a pobreza infantil tem uma taxa mais alta que a pobreza em geral.

Parece-nos claro que as medidas políticas adotadas para lidar com a crise têm vindo a ter um efeito de redução do número de beneficiários e nos montantes envolvidos, como mostram Wall, Almeida, Vieira e Cunha (2015: 22). Estas autoras 
consideram mesmo que "O Rendimento Social de Inserção (RSI) é a prestação social que tem sido alvo de um maior corte financeiro na despesa pública do Estado desde 2010." (2015: 22).

Esta explicação dá conta da primeira contradição, mas não da referente à redução da proporção das crianças entre os beneficiários. A questão tem por nós sido colocada junto de técnicos e responsáveis intermédios da Ação Social envolvidos na aplicação do RSI nos Açores, e os nossos interlocutores não tinham identificado o problema, e quando confrontados com ele não encontraram explicação.

Pode-se colocar a hipótese de que a origem do problema é, apesar de tudo, a mesma, isto é, as transformações que esta medida de apoio social tem sofrido têm penalizado mais as famílias com crianças, levando à redução do seu número entre os beneficiários. ${ }^{14}$

A análise das principais mudanças legislativas até 2013 parece corroborar esta hipótese. Assim, (i) a inclusão de todos os habitantes da mesma casa no cálculo da prestação tem impacto nas mulheres que vivem com os seus filhos em casa de familiares (famílias monoparentais femininas), reduzindo contabilisticamente o número de famílias monoparentais pobres; (ii) esta mesma medida alarga os rendimentos contabilizados para os agregados familiares numerosos em coabitação levando a uma maior probabilidade de assim ficarem acima do valor de referência. Ora, essas são, como vimos, os dois tipos de famílias com crianças com maior probabilidade de serem pobres e, por isso, de terem acesso ao RSI; (iii) a redução do indexante das prestações sociais no orçamento de 2013 tende a excluir as famílias numerosas em que existem rendimentos de trabalho. A partir desse ano é preciso haver menos rendimentos para se ter acesso à prestação.

\section{Conclusão}

Em conclusão, qual a fiabilidade das estatísticas sobre a pobreza infantil em Portugal? Apesar de todas as cautelas conceptuais que são necessárias para analisar os dados que nos são fornecidos pelo INE como referentes à pobreza infantil, este conceito tem diversas virtudes. Desde logo, as suas limitações são atenuadas pelo facto de incluir um conjunto de indivíduos que partilha a menoridade social como característica ou, noutros termos, a dependência em relação a outros. Esta característica não é apenas teórica, mas tem óbvias consequências na vida dos indivíduos. Por outro lado, o conceito de pobreza infantil tem uma virtude muito clara: existe e é operacionalizável. Quer dizer, não vale a pena envolvermo-nos em complexas elaborações teóricas sem dados que nos permitam a confrontação empírica. Os dados fornecidos pelo INE permitem realizar este último exercício.

Não obstante, para nós, a principal limitação à fiabilidade das análises da pobreza infantil a partir dos dados do INE respeita ao facto de estes apenas permitirem uma

14 Esta hipótese foi colocada por Carlos Farinha Rodrigues, em Ponta Delgada em fevereiro de 2016, quando interpelado pelo autor deste texto. 
primeira aproximação às situações de pobreza (e de pobreza infantil). Corremos o risco de, com eles, desenvolvermos a sensação de conhecer um fenómeno social do qual, verdadeiramente, só sabemos que é importante e só conhecemos as suas características mais gerais. De facto, o que sabemos sobre a pobreza em Portugal é muito pouco, apesar dos estudos que sobre ela vão sendo realizados, ainda que esse pouco nos permita, sobretudo, perceber que se trata de uma questão central no desenvolvimento do país, onde a pobreza infantilé particularmente relevante e envolve categorias diversas de indivíduos.

Os dados obtidos possibilitam-nos colocar imediatamente a questão do papel do estado na menorização e erradicação da pobreza, e em particular da pobreza infantil. Esta não é a única questão relevante, pois também estão em causa os mecanismos geradores do elevado volume de pobreza existente na sociedade portuguesa e o potencial papel do estado na sua atenuação e remediação. Isto é, também está em causa o problema das desigualdades de distribuição de rendimentos e das desigualdades de oportunidades.

Neste artigo debruçámo-nos apenas sobre a primeira questão a partir de um caso concreto. É claro que as políticas dirigidas à infância não têm vindo a contribuir para a redução da pobreza infantil, considerando as estatísticas do INE, em flagrante contraste com o que se passou em relação aos idosos. Aliás, Arnold e Rodrigues (2015) consideram mesmo que o sistema de apoio social em Portugal se encontra edificado de forma a beneficiar os mais velhos. Os dados do RSI são um exemplo prático das dificuldades que o estado tem em desenvolver políticas de mitigação e erradicação da pobreza infantil: se o número de beneficiários tem vindo a reduzir-se, crianças e jovens têm sido especialmente afetados. As modificações desenvolvidas na medida parecem estar a afetar mais as famílias com crianças, colocando-as acima do limiar a partir do qual se tem direito à prestação.

Esta prevalência da pobreza infantil contrasta com a natalidade no país, dado que o índice sintético de fecundidade (número médio de crianças nascidas por cada mulher em idade fértil) foi em 2015 de 1,3, isto quando para se assegurar a substituição de gerações é preciso que cada mulher tenha em média 2,1 filhos (vide Pordata). Num contexto social em que objetivamente faltam crianças não tem sido possível poupar boa parte das que existem à situação de pobreza.

\section{Referências bibliográficas}

Almeida, Ana Nunes de (2009), Para Uma Sociologia da Infância. Jogos de Olhares, Pistas para a Investigação, Lisboa, ICS.

Alves, Nuno (2015), "A dinâmica da pobreza em Portugal", em Fernando Diogo, Alexandra Castro e Pedro Perista, Pobreza e Exclusão Social em Portugal. Contextos, Transformações e Estudos, Ribeirão, Húmus, pp. 65-78.

Arnold, Jens, e Carlos Farinha Rodrigues (2015), "Reducing inequality and poverty in Portugal", OECD Economics Department Working Papers N. 1258. 
Bastos, Amélia (2015), “Pobreza infantil: diagnóstico e reflexão sobre os indicadores de aferição", em Fernando Diogo, Alexandra Castro e Pedro Perista, Pobreza e Exclusão Social em Portugal. Contextos, Transformações e Estudos, Ribeirão, Húmus, pp. 101-113.

Bastos, Amélia, e Francisco Nunes (2009), “Child poverty in Portugal: dimensions and dynamics", Childhood, 16 (1), pp. 67-87.

Batista, Isabel, e Pedro Perista (2010), “A estruturalidade da pobreza e da exclusão social na sociedade portuguesa: conceitos, dinâmicas e desafios para a acção", Fórum Sociológico, 20, pp. 39-46.

Branco, Franciso (2015), "A procura da assistência social em Portugal como revelador da pobreza e da vulnerabilidade social", em Fernando Diogo, Alexandra Castro e Pedro Perista, Pobreza e Exclusão Social em Portugal. Contextos, Transformações e Estudos, Ribeirão, Húmus, pp. 231-249.

Bruto da Costa, Alfredo (2015), "Prefácio", em Fernando Diogo, Alexandra Castro e Pedro Perista, Pobreza e Exclusão Social em Portugal. Contextos, Transformações e Estudos, Ribeirão, Húmus, pp. 7-16.

Capucha, Luís (2005), Desafios da Pobreza. Oeiras, Celta Editora.

Capucha, Luís (2015), “Conhecimento para a ação: avanços, lacunas e caminhos para o estudo da pobreza", em Fernando Diogo, Alexandra Castro e Pedro Perista, Pobreza e Exclusão Social em Portugal. Contextos, Transformações e Estudos, Ribeirão, Húmus, pp. 49-63.

D’Agostino, Serge, e Nicole Duvert (2008), La Pauvreté, Rosny, Bréal.

Diogo, Fernando (2007), Pobreza, Trabalho, Identidade. Oeiras, Celta Editora.

Diogo, Fernando (2010), "From child poverty to the profiles of child poverty: a pathway to be explored", Problemy Wczesnej Edukacji / Issues in Early Education, Rok VI, 1 (11), pp. 20-31.

Diogo, Fernando (2016), “Pobreza, Rendimento Social de Inserção e crianças: o que há de novo?", em Amélia Bastos e Fátima Veiga, Um Olhar sobre o Bem-Estar das Crianças e Jovens segundo a Perspetiva dos Direitos da Criança, Ribeirão, Húmus.

Diogo, Fernando, Alexandra Castro, e Pedro Perista (2015), “Introdução”, em Fernando Diogo, Alexandra Castro e Pedro Perista, Pobreza e Exclusão Social em Portugal. Contextos, Transformações e Estudos, Ribeirão, Húmus, pp. 17-26.

OECD (2009), Doing Better for Children, Paris, OCDE Publishing.

OECD (2011), Divided We Stand. Why Inequality Keeps Rising? Paris, OECD Publishing.

Pereira, Elvira (2010), Pobreza e Ruralidade. Uma Análise Espacial em Portugal Continental, Lisboa, ISEG, dissertação de doutoramento.

Pereirinha, José António (coord.), Francisco Nunes, Amélia Bastos, Sara Falcão Casaca, e Carla Machado (2008), Género e Pobreza. Impacto e Determinante da Pobreza no Feminino, Lisboa, Comissão para a Cidadania e Igualdade de Género.

Rodrigues, Carlos Farinha (coord.), Rita Figueiras, e Vitor Junqueiro (2016), Introdução ao Estudo: Desigualdade de Rendimento e Pobreza em Portugal 2009-2014, Lisboa, Fundação Francisco Manuel dos Santos.

Sarmento, Manuel Jacinto, Natália Fernandes, e Gabriela Trevisan (2015), “A redefinição das condições estruturais da infância e a crise económica em Portugal", em Fernando Diogo, Alexandra Castro e Pedro Perista, Pobreza e Exclusão Social em Portugal. Contextos, Transformações e Estudos, Ribeirão, Húmus, pp. 81-99. 
UNICEF (2016), Fairness for Children. A League Table of Inequality in Child Well-Being in Rich Countries. Innocenti Report Card 13, Children in the Developed World, Florença, UNICEF Office of Research - Innocenti.

Wall, Karin, Ana Nunes de Almeida, Maria Manuel Vieira, Vanessa Cunha (coords.), Leonor Rodrigues, Filipa Coelho, Mafalda Leitão, e Susana Atalaia (2015), Impactos da Crise nas Crianças Portuguesas. Indicadores, Políticas, Representações, Lisboa, ICS.

Fernando Diogo. Docente na Universidade dos Açores, e investigador no CICS.NOVA.UAc/CICS.UAc. E-mail: fernando.ja.diogo@uac.pt

Receção: 16 de março de 2017 Aprovação: 2 de junho de 2017 